\title{
Extracranial-Intracranial Cerebral Revascularization: Indications and Results
}

\section{Revascularização cerebral extracraniana-intracraniana: indicações e resultados}

\author{
Jair Leopoldo Raso ${ }^{1}$ Paulo Mallard Scaldaferri ${ }^{2}$ Rafael de Albuquerque Barbosa ${ }^{2}$ \\ ${ }^{1}$ Instituto Mineiro de Neurocirurgia, Biocor Instituto, Belo Horizonte, \\ Brazil \\ ${ }^{2}$ Specialization Program in Neurosurger, Instituto Mineiro de \\ Address for correspondence Jair Leopoldo Raso, MD, PhD, Alameda \\ da Serra 400/404, Nova Lima, Belo Horizonte, MG, CEP 34000000 , \\ Brazil (e-mail: jraso@uol.com.br).
}

Neurocirurgia, Biocor Instituto, Belo Horizonte, Brazil

Arq Bras Neurocir 2015;34:110-115.

\begin{abstract}
Keywords

- cerebral revascularization

- extracranialintracranial bypass

- superficial temporal artery

- middle cerebral artery
\end{abstract}

Resumo
Objective To present a case-series study of extracranial-intracranial (EC-IC) bypass procedures performed in our service and evaluate indications and results.

Method The medical records of 30 patients undergoing $32 \mathrm{EC}-\mathrm{IC}$ anastomosis procedures were evaluated. Seventeen patients were male (56.6\%). The age ranged from 26 to 85 years (mean: 58.2). The follow-up ranged from 1 to 211 months (mean: 54 ). We evaluated the indications and complications of the surgical procedures.

Results The bypass procedures comprised 28 STA-MCA anastomosis $(87,5 \%)$ and four posterior circulation anastomosis. The main indications included cervical internal carotid artery occlusion (19 cases), Moyamoya disease (3 cases), giant aneurysms (3 cases), intracranial arterial stenosis ( 2 cases), and vertebral-basilar insufficiency ( 3 cases). On follow-up, graft patency was $93.7 \%$, confirmed in half of the cases by arterial digital subtraction angiography, magnetic resonance angiography, and CT angiography. There was no surgical mortality. Three patients had PO complications (9.3\%), including one case of ischemia (3.1\%).

Conclusion The EC-IC bypass is a procedure with low morbidity and mortality. The indication of EC-IC bypass surgery for cerebral atherosclerotic disease should not be generalized. The EC-IC bypass can be indicated for cerebral revascularization in Moyamoya disease, intracranial stenosis, and in the management of complex aneurysms. This procedure can be an alternative in the treatment of vertebral-basilar insufficiency.

Objetivo Apresentar uma série de casos de anastomose extra-intracraniana (EC-IC) avaliando suas indicações e resultados.

Método Foram avaliados retrospectivamente os prontuários de 30 pacientes submetidos a 32 procedimentos de anastomose EC-IC. Dezessete pacientes eram do sexo received

May 12, 2014

accepted

March 31, 2015
DOI http://dx.doi.org/

$10.1055 / \mathrm{s}-0035-1554738$. ISSN 0103-5355.
Copyright $(2015$ by Thieme Publicações License terms

Ltda, Rio de Janeiro, Brazil
(®) $\Theta \circledast$ 


\section{Palavras-chave \\ - revascularização cerebral \\ - bypass extra- intracraniano \\ - artéria temporal superficial \\ - artéria cerebral média}

masculino $(56,6 \%)$ com média de idade de 58,2 anos. O período de seguimento variou de um a 211 meses (média: 54). Foram avaliadas as indicações e complicações dos procedimentos cirúrgicos.

Resultados Foram realizadas 28 anastomoses entre a artéria temporal superficial e a cerebral média $(87,5 \%)$ e quatro anastomoses na circulação posterior. As principais indicações foram oclusão de carótida interna cervical (19 casos), doença de Moyamoya ( 3 casos), aneurismas gigantes ( 3 casos), estenose arterial intracraniana (2 casos) e insuficiência vertebrobasilar ( 3 casos). A patência tardia do bypass confirmada em metade dos casos por angiografia, angiorressonância ou angiotomografia foi de $93,7 \%$. Não houve mortalidade cirúrgica. Um paciente $(3,1 \%)$ apresentou isquemia no pósoperatório. Outros dois pacientes $(6,2 \%)$ apresentaram complicações não isquêmicas. Conclusões A revascularização EC-IC é procedimento de baixa morbidade e mortalidade. A indicação do procedimento para oclusão carotídea não pode ser generalizada. O bypass EC-IC pode ser indicado na doença de Moyamoya, nas estenoses intracranianas e no manejo de aneurismas complexos. Pode ser alternativa no tratamento da insuficiência vertebrobasilar.

\section{Introduction}

Cerebral revascularization by extracranial-to-intracranial (EC-IC) anastomosis between the superficial temporal artery (STA) and the middle cerebral artery (MCA) is not a commonly performed procedure in most neurosurgery training centers.

The initial enthusiasm for the new technique proposed by Yasargil ${ }^{1}$ was dampened after the results of the first multicenter randomized controlled trial on cerebral revascularization, which was funded by the National Institutes of Health $(\mathrm{NIH})^{2}$

However, the methodology of that study received much criticism and the validity of its conclusions was called into question. In addition, the results of other multicenter studies proving the benefits of another type of revascularization, endarterectomy to treat carotid stenosis, reawakened interest in the EC-IC bypass technique.

The results of another multicenter study evaluating the indication of EC-IC bypass surgery for carotid artery (CA) occlusion have been published recently. ${ }^{3}$ Although EC-IC bypass was shown to increase cerebral blood flow, the procedure was not superior to best medical treatment in stroke prevention.

In addition to the indication for atherosclerotic disease, EC-IC bypass is indicated for the treatment of Moyamoya disease, arterial stenosis due to neoplasia, and in the management of giant or complex brain aneurysms.

We present a case-series study of EC-IC bypass procedures performed in our service and evaluate indications and results. We have included the cases of EC-IC bypass for the posterior circulation.

\section{Methods}

We evaluated retrospectively the medical records of 30 patients undergoing $32 \mathrm{EC}-\mathrm{IC}$ anastomosis procedures by the senior author in the period between January 1996 and December 2013. Seventeen patients were male (56.6\%). The age ranged from 26 to 85 years (mean: 58.2). The follow-up ranged from 1 to 211 months (mean: 54). We evaluated the indications and complications of the surgical procedures. Late patency of the anastomosis has been verified by imaging tests (angiography, angiotomography, or angio-MRI). During the follow-up period we evaluated the incidence of stroke and death.

This study was approved by the Research Ethics Committee of the Biocor Institute. All patients signed informed consent form.

\section{Technique}

Antiplatelet drugs were discontinued 7 days prior to the procedure. The patients received bridge therapy with $40 \mathrm{mg}$ subcutaneous enoxaparin, as done for endarterectomy. ${ }^{4}$ Intraoperative monitoring, fluid loading, and choice of anesthetic agents were left to the discretion of the anesthesiologist, with the recommendation of maintaining normocapnia. All the patients were given antibiotics 1 hour before surgery through the first postoperative (PO) day. Only one anastomosis was done in each patient. Either the frontal or temporal branch of the STA was dissected; the connective tissue surrounding the vessel adventitia was spared. The end centimeter of the arterial graft was prepared in a "fish mouth" shape. Arterial blood flow was stopped with temporary clipping. A circumferential frontotemporal craniotomy was done (-Fig. 1). The dura mater was open and a cortical branch of the MCA was dissected to receive the STA graft. This segment was isolated with the aid of small temporary clips. A longitudinal arteriotomy was performed proportional to the luminal diameter of the temporal artery graft. An end-toside anastomosis was done using interrupted 9.0 Prolene or nylon sutures. The patient was not heparinized during the anastomosis procedure. After completion of the 


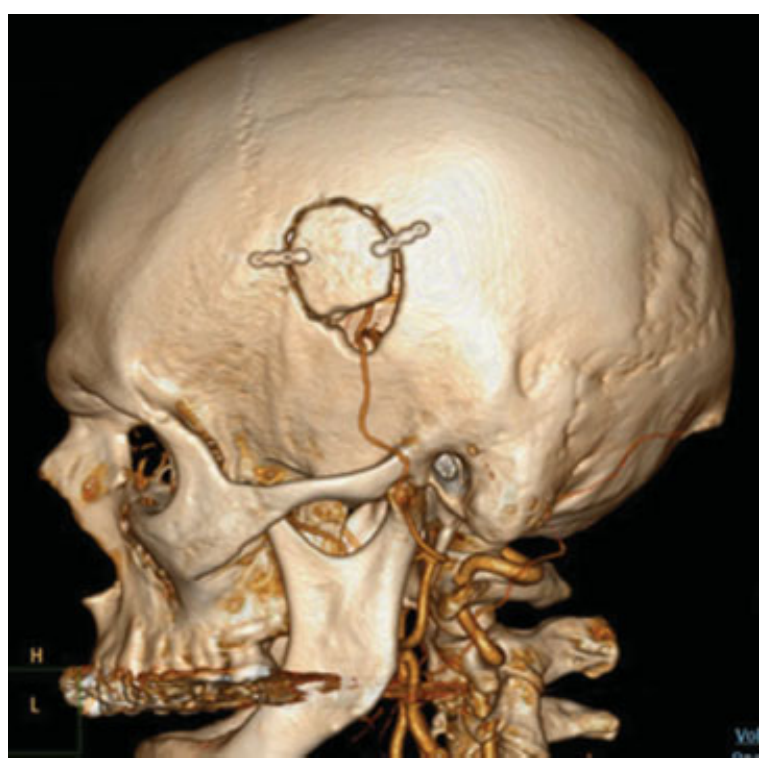

Fig. 1 Craniotomy bypass. CT angiotomography showing circumferential craniotomy.

anastomosis, the temporary clips were removed. Any bleeding on the suture line was controlled by gentle compression with Cottonoids and Surgicel. The graft patency was tested by stopping the MCA flow upstream of the anastomosis and assessing the arterial flow in the segment distal to the anastomosis. On the first PO day, the patients were started on $325 \mathrm{mg}$ oral aspirin or $75 \mathrm{mg}$ clopidogrel daily.

\section{Results}

The bypass procedures comprised 28 STA-MCA anastomoses (87.5\%) and 4 posterior circulation anastomoses. Of the latter, three procedures involved the occipital artery and the vertebral artery, and one involved the occipital artery and a postmeatal segment of the anterior inferior cerebellar artery (AICA). The indications were cervical internal CA occlusion-unilateral (16 cases) and bilateral (3 cases), pseudo-aneurysm of the cervical internal CA (1 case), severe stenosis or occlusion of the intracranial internal CA from Moyamoya disease (3 cases), MCA stenosis ( 2 cases), cavernous internal CA stenosis due to neoplasia (1 case), giant aneurysm in cavernous internal CA (2 cases), vertebralbasilar insufficiency ( 3 cases), and giant aneurysm of the $o$ basilar artery (1 case). Immediate graft patency was ascertained in all the cases by observation, as described. On follow-up, graft patency was confirmed in half of the cases by arterial digital subtraction angiography in 10 cases, magnetic resonance angiography in 4 cases, and CT angiography in 2 cases. The long-term graft patency rate based on those imaging studies was $93.7 \%$.

There was no surgical mortality. Three patients had PO complications (9.3\%), including one case of ischemia (3.1\%). One patient had an acute subdural hematoma requiring surgical drainage; late in the PO course, the same patient developed a pseudoaneurysm at the site of the anastomosis, which was surgically treated. There was one case of cerebrospinal fluid fistula with central nervous system infection, which responded well to medical treatment. Fistula repair surgery was not necessary. One patient developed mild crural paresis in the immediate PO period, which did not prevent ambulation. No stroke or death was observed in the follow-up period.

\section{Discussion}

Since EC-IC bypass was proposed by Yasargil ${ }^{1}$ in 1969 , the reaction to this cerebral revascularization technique, also known as low-flow bypass, has varied from heightened enthusiasm to total rejection.

In the 1970s, the EC-IC bypass procedure became mandatory in the training of residents and was widely performed in neurosurgical services worldwide. Despite being a lowmorbidity procedure, the indications and results of EC-IC bypass were not well established.

The NIH funded an international, multicenter, randomized controlled trial to determine whether cerebral revascularization by the EC-IC bypass technique would reduce the risk of cerebrovascular events or death in patients with distal CA stenosis, CA occlusion, or MCA stenosis. ${ }^{2}$ The publication of that study results, in 1985, had a great impact on neurosurgical practice, as it concluded that EC-IC bypass surgery offered no benefit over medical treatment in the prevention of cerebrovascular events and death. Following that study, EC-IC bypass procedures became an exception and were used in select cases and in few centers of reference.

Nevertheless, several authors pointed to methodological flaws in that study. ${ }^{5-7}$ The most common failure discussed was the analysis of the complications, which was done on an intent-to-treat basis. Thus, 81 cases of stroke were counted in the group of 663 surgical patients (12.2\%). However, 16 of those patients had suffered a stroke after randomization but before surgery. If only the cases of post-surgery strokes were considered, stroke incidence rates would fall to 9.9\% (65 cases of stroke in 652 operations).

The publication of the results of randomized studies on endarterectomy, another modality of revascularization, was also used as criticism to the conclusions of the international study and contributed to rekindle the interest in low-flow bypass surgery. The Asymptomatic Carotid Atherosclerosis Study (ACAS), ${ }^{8}$ North American Symptomatic Carotid Endarterectomy Trial (NASCET), ${ }^{9}$ and European Carotid Surgery Trial (ECST) $)^{10}$ are the most notable of those studies.

Indicated for moderate to severe cervical CA stenosis, even if asymptomatic, endarterectomy proved to be more efficacious than the medical treatment alone. Similarly, cervical CA angioplasty with stenting was shown to be efficacious for stroke prevention in severe carotid stenosis. ${ }^{11,12}$

Carotid occlusion in patients with atherosclerosis is a risk factor for a stroke ${ }^{13}: 27$ to $38 \%$ of the patients with acute CA occlusion suffer a stroke, and the annual risk ranges from 2 to $5.5 \%$. The risk of death after a diagnosis of carotid occlusion 
ranges from 30 to $40 \%$ in 5 years. In addition, the risk of endarterectomy or angioplasty for treatment of carotid stenosis contralateral to the occlusion site increases significantly.

Because neither endarterectomy nor angioplasty is indicated for carotid occlusion, bypass surgery began to be regarded as a potential therapeutic option.

To test the hypothesis that EC-IC bypass surgery would benefit patients with carotid occlusion, the NIH funded the Carotid Occlusion Surgery Study (COSS). ${ }^{3}$ This randomized study was conducted between 2002 and 2010, involving 49 centers in the United States and Canada. All the cases of stroke and death within 30 PO days were evaluated, as well as the incidence of ipsilateral stroke after 2-year randomization.

Despite the excellent graft patency rate and significant improvement in cerebral blood flow as demonstrated by positron emission tomography (PET) scanning, the study data did not demonstrate superiority of the surgical procedure compared with best medical treatment.

Two-year rates for the primary end point were $21 \%$ in the surgical group and $22.7 \%$ in the medical group. The incidence rate of ipsilateral stroke after 30 days was $14.3 \%$ in the surgical group and $2 \%$ in the medical group.

In our series, CA occlusion (-Fig. 2) was the principal indication for EC-IC bypass (19 cases, 59.3\%). Because PET scanning was not available, we used brain perfusion singlephoton emission computed tomography (SPECT) to confirm hypoperfusion in all cases. Only one patient suffered a stroke in the 30-day PO period (3.1\%). This patient had left-sided cervical CA occlusion manifested as aphasia. During the immediate PO period, the patient developed crural paresis. Magnetic resonance imaging (MRI) showed a small area of parietal ischemia.

The bypass surgery for atherosclerotic disease was the object of two large randomized trials and failed to show a significant benefit. It is speculated that a subgroup of patients with refractory ischemic symptoms could benefit from the bypass provided that perioperative complication rates are low. ${ }^{14,15}$ However, given the results of the trials, there is no established recommendation for revascularization in atherosclerotic disease. Despite its limited indication for atherosclerotic disease, revascularization should not be abandoned. First, because there is a group of patients who do benefit from this surgical technique, whose indications must be individualized. Second, because the EC-IC bypass can be of great utility in other pathologic conditions.

The EC-IC bypass procedure may be a valid alternative in intracranial arterial stenosis. The findings of the SAMMPRIS trial support that aggressive medical management should be used rather than angioplasty in patients with intracranial arterial stenosis. ${ }^{16}$ The occurrence of any stroke and major hemorrhage was higher in the percutaneous angioplasty group than in the medical group. Therefore, one may consider EC-IC bypass to treat intracranial arterial stenosis. In our series, we performed EC-IC bypass surgery on two patients with severe symptomatic stenosis in the MCA segment with good outcome.

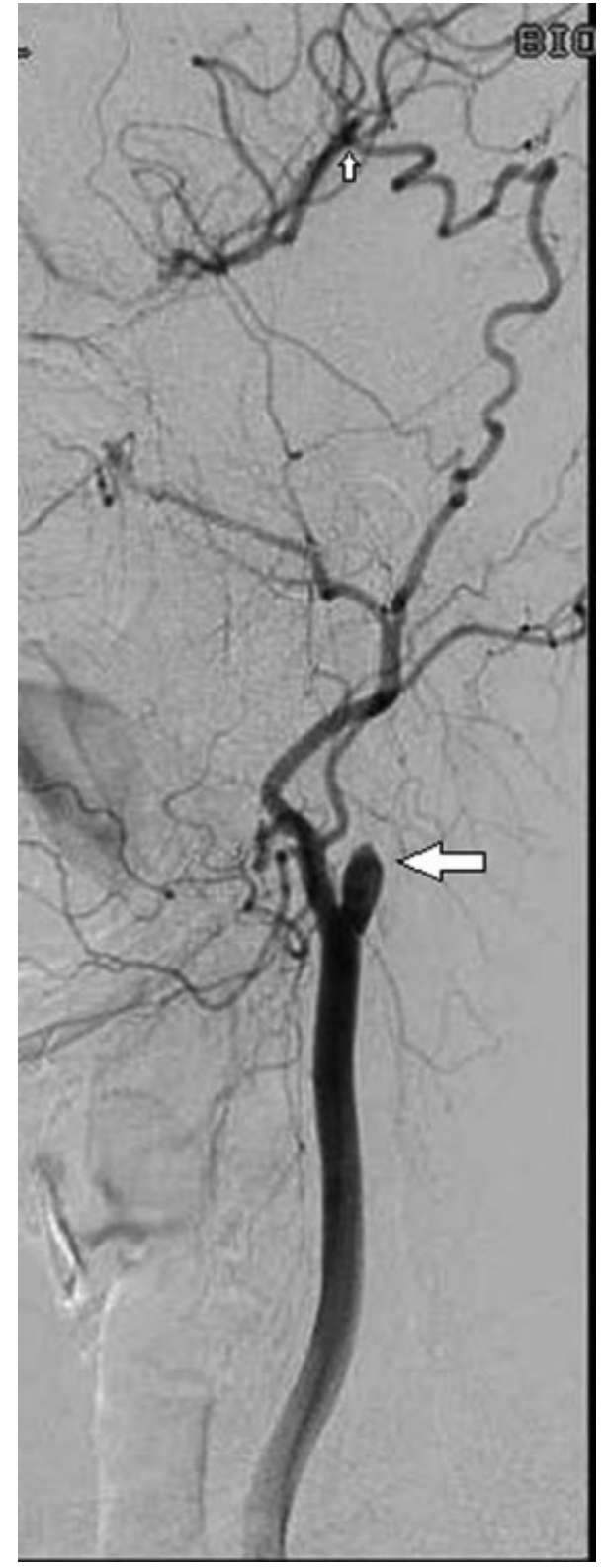

Fig. 2 Superficial temporal artery (STA) and middle cerebral artery (MCA). Remark to occlusion of internal cervical carotid (big arrow) and swallow of MCA by anastomosis (small arrow).

Moyamoya disease is also an indication for EC-IC bypass. It causes major hemodynamic alterations in cerebral circulation involving the CA supraclinoid segments. The abundant network of minute collateral vessels surrounding the arterial occlusion, which names the disease because of its appearance of smoke ("Moyamoya" means "a puff of smoke"), is not sufficient to ensure cerebral blood flow. Revascularization has proved useful in these cases. ${ }^{17,18}$ In our series, Three adult patients with Moyamoya disease underwent revascularization. They had bilateral occlusion of the intracranial internal CA with the typical angiographic pattern of the disease.

The EC-IC bypass procedure can also be used for revascularization when the sacrifice of a major blood vessel is necessary, as in the treatment of some giant or complex 


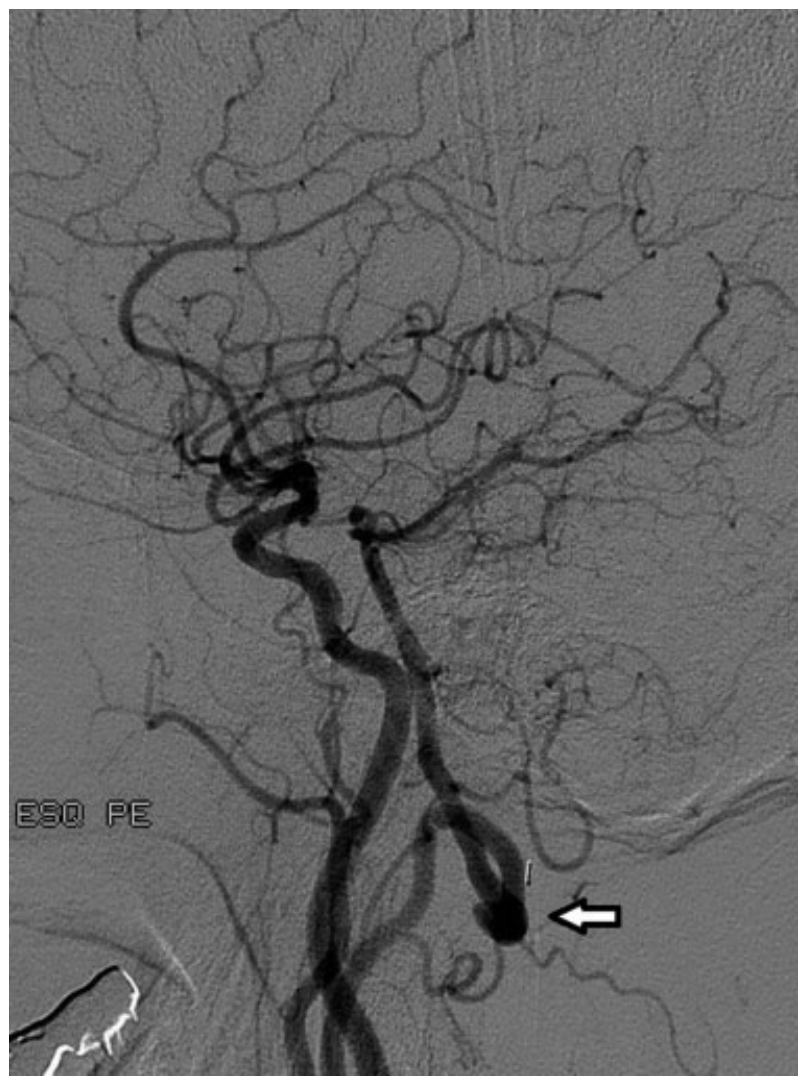

Fig. 3 Anastomosis of occipital artery with extracranial horizontal segment of vertebral artery (arrow). Remark to swallow of system vertebral basilar by anastomosis.

intracranial aneurysms. Following that indication, we performed the bypass in two cases of giant aneurysm in the cavernous internal CA as part of the strategy of cervical internal CA occlusion to manage the aneurysm. The same rationale supported the indication of bypass for posterior circulation in the case of a giant aneurysm in the middle onethird of the basilar artery. We did a bypass of the occipital artery to the AICA at the cerebellopontine angle. In a second stage, the basilar artery upstream of the anastomosis was occluded using endovascular technique.

The literature data are insufficient to support an evaluation of the indication and efficacy of revascularization in the posterior fossa. We indicated posterior fossa revascularization due to vertebral-basilar insufficiency in three cases in our series. We performed anastomosis of the occipital artery with the horizontal segment of the extracranial vertebral artery (-Fig. 3). This technique was inspired by a case report by Hadley et al, who used it in a case of blunt trauma to the vertebral artery. $^{19}$

Because the chief indication for revascularization is to prevent cerebral ischemia, most reports of PO complications focus mainly on ischemic events. In the first trial, regardless of the methodology adopted, the rate of ischemic complications was high: based on the intent-to-treat analysis, the stroke rate was $12.2 \%$. When the cases of stroke prior to surgery were disregarded, still the ischemic complication rate was $9.9 \%$. This complication was fatal in four cases
(0.6\%). ${ }^{2}$ The COSS study found $14.3 \%$ of ipsilateral strokes in the group of surgically treated patients. ${ }^{3}$

In our series, one patient had a minor stroke (3.1\%). However, the evaluation of this low incidence rate should take into consideration the limitations of our work: (1) a retrospective study, (2)EC-IC bypass was not indicated only for atherosclerotic disease, and (3) no control group was included.

The occurrence of non ischemic complications should also deserve attention. Samson and Boone reported $13.6 \%$ of non ischemic complications in 376 operations. ${ }^{20}$ Schick et al reported a $6 \%$ incidence rate of subdural hematoma in their series of 47 cases. ${ }^{21}$ In our series, two patients developed non ischemic complications (6.45\%).

\section{Conclusion}

The EC-IC bypass is a procedure with low morbidity and mortality. The indication of EC-IC bypass surgery for cerebral atherosclerotic disease should not be generalized. Some patients could benefit from cerebral revascularization and should be evaluated on an individual basis.

The EC-IC bypass can be indicated for cerebral revascularization in Moyamoya disease, intracranial stenosis, and in the management of complex aneurysms. This procedure can be an alternative in the treatment of vertebral-basilar insufficiency.

\section{References}

1 Yasargil MD. Anastomosis between the superficial temporal artery and a branch of the middle cerebral artery. In: Yasargil MD, ed. Microsurgery Applied to Neuro-surgery. Stuttgart, Germany: Georg Thieme; 1969:105-115

2 The International Cooperative Study of Extracranial/Intracranial Arterial Anastomosis (EC/IC Bypass Study). Methodology and entry characteristics. The EC/IC Bypass Study group. Stroke 1985;16(3):397-406

3 Powers WJ, Clarke WR, Grubb RL Jr, Videen TO, Adams HP Jr, Derdeyn CP; COSS Investigators. Extracranial-intracranial bypass surgery for stroke prevention in hemodynamic cerebral ischemia: the Carotid Occlusion Surgery Study randomized trial. JAMA 2011;306(18):1983-1992

4 Raso JL, Darwich RZ, Lucca Fd Jr, et al. Bridge-therapy with enoxaparin in the preoperative period of endarterectomy. Arq Neuropsiquiatr 2010;68(5):775-777

5 Day AL, Rhoton AL Jr, Little JR. The extracranial-intracranial bypass study. Surg Neurol 1986;26(3):222-226

6 Ausman JI, Diaz FG. Critique of the extracranial-intracranial bypass study. Surg Neurol 1986;26(3):218-221

7 Awad IA, Spetzler RF. Extracranial-intracranial bypass surgery: a critical analysis in light of the International Cooperative Study. Neurosurgery 1986;19(4):655-664

8 Endarterectomy for asymptomatic carotid artery stenosis. Executive Committee for the Asymptomatic Carotid Atherosclerosis Study. JAMA 1995;273(18):1421-1428

9 Barnett HJ, Taylor DW, Eliasziw M, et al. Benefit of carotid endarterectomy in patients with symptomatic moderate or severe stenosis. North American Symptomatic Carotid Endarterectomy Trial Collaborators. N Engl J Med 1998;339(20):1415-1425

10 Randomised trial of endarterectomy for recently symptomatic carotid stenosis: final results of the MRC European Carotid Surgery Trial (ECST). Lancet 1998;351(9113):1379-1387 
11 Berkefeld J, Chaturvedi S. The International Carotid Stenting Study and the North American Carotid Revascularization Endarterectomy versus Stenting Trial: fueling the debate about carotid artery stenting. Stroke 2010;41(11):2714-2715

12 George JC, White CJ. Carotid artery stenting lessons From CREST (Carotid Revascularization Endarterectomy Versus Stenting Trial). JACC Cardiovasc Interv 2010;3(9):988-990

13 Bryan DS, Carson J, Hall H, et al. Natural history of carotid artery occlusion. Ann Vasc Surg 2013;27(2):186-193

14 Amin-Hanjani S, Charbel FT. Is extracranial-intracranial bypass surgery effective in certain patients? Neurol Clin 2006;24(4): 729-743

15 Amin-Hanjani S, Barker FG II, Charbel FT, Connolly ES Jr, Morcos JJ, Thompson BG; Cerebrovascular Section of the American Association of Neurological Surgeons; Congress of Neurological Surgeons. Extracranial-intracranial bypass for stroke-is this the end of the line or a bump in the road? Neurosurgery 2012;71(3):557-561

16 Derdeyn CP, Chimowitz MI, Lynn MJ, et al; Stenting and Aggressive Medical Management for Preventing Recurrent Stroke in Intra- cranial Stenosis Trial Investigators. Aggressive medical treatment with or without stenting in high-risk patients with intracranial artery stenosis (SAMMPRIS): the final results of a randomised trial. Lancet 2014;383(9914):333-341

17 Sakamoto H, Kitano S, Yasui T, et al. Direct extracranial-intracranial bypass for children with Moyamoya disease. Clin Neurol Neurosurg 1997;99(Suppl 2):S128-S133

18 Morgan MK, Ferch RD, Little NS, Harrington TJ. Bypass to the intracranial internal carotid artery. J Clin Neurosci 2002;9(4): 418-424

19 Hadley MN, Spetzler RF, Masferrer R, Martin NA, Carter LP. Occipital artery to extradural vertebral artery bypass procedure. Case report. J Neurosurg 1985;63(4):622-625

20 Samson DS, Boone S. Extracranial-intracranial (EC-IC) arterial bypass: past performance and current concepts. Neurosurgery 1978;3(1):79-86

21 Schick U, Zimmermann M, Stolke D. Long-term evaluation of EC-IC bypass patency. Acta Neurochir (Wien) 1996;138(8):938-942, discussion 942-943 